\title{
Atuação da equipe de enfermagem em cuidados paliativos
}

\author{
Performance of the nursing team in palliative care \\ Desempeño del equipo de enfermería en cuidados paliativos
}

Recebido: 01/02/2021 | Revisado: 07/02/2021 | Aceito: 08/02/2021 | Publicado: 15/02/2021

\author{
Brenda Melo Costa \\ ORCID: https://orcid.org/ 0000-0002-5824-8354 \\ Fundação Educacional do Município de Assis, Brasil \\ E-mail: brendamello044@gmail.com \\ Daniel Augusto da Silva \\ ORCID: https://orcid.org/0000-0002-2716-6700 \\ Fundação Educacional do Município de Assis, Brasil \\ E-mail: daniel.augusto@unifesp.br
}

\begin{abstract}
Resumo
Objetivo: analisar a atuação de Enfermagem no contexto do Cuidado Paliativo. Metodologia: trata-se de um estudo observacional, transversal, de abordagem qualitativa, realizado no contexto da atenção secundária a saúde, em uma Unidade de Pronto Atendimento de cidade do centro-oeste paulista. A coleta dos dados ocorreu no primeiro semestre de 2020, por meio de entrevista com instrumento elaborado pelos autores, composto por questões para caracterização dos participantes e sobre a percepção quanto ao atendimento em cuidados paliativos. Os dados coletados foram analisados utilizando análise de conteúdo, modalidade temático categorial. Resultados: participaram 12 profissionais de nível médio em Enfermagem, com idade média de 33 anos, maioria do sexo feminino (91,7\%). Foram elegidas três categorias: 1. A formação em cuidados paliativos; 2 - O conhecimento sobre cuidados paliativos; 3 - A atuação no atendimento em cuidados paliativos. Considerações finais: o presente estudo possibilitou compreender a dificuldade que os profissionais de enfermagem encontram diante da temática de cuidados paliativos. Alguns profissionais mostraram certa falta de conhecimento tanto teórico quanto prático sobre a assistência necessária para esse tipo de cuidado. Além da falta de conhecimento por parte de alguns; outros apresentaram uma forte sensibilidade em relação a temática. Apesar de saber que a morte se faz presente no dia-a-dia desses profissionais de enfermagem, muitos não se consideram preparados para este momento.
\end{abstract}

Palavras-chave: Cuidados paliativos; Enfermagem; Técnicos de enfermagem; Doente terminal.

\begin{abstract}
Objective: to analyze the performance of Nursing in the context of Palliative Care. Methodology: this is an observational, cross-sectional study with a qualitative approach, carried out in the context of secondary health care, in an Emergency Care Unit in a city in the Midwest of São Paulo. Data collection took place in the first semester of 2020, through an interview with an instrument prepared by the authors, composed of questions for the characterization of the participants and about the perception regarding assistance in palliative care. The collected data were analyzed using content analysis, categorical thematic modality. Results: 12 mid-level nursing professionals participated, with an average age of 33 years, mostly female (91.7\%). Three categories were chosen: 1 . Training in palliative care; 2 Knowledge about palliative care; 3 - Performance in palliative care. Final considrations: the present study made it possible to understand the difficulty that nursing professionals encounter when faced with the theme of palliative care. Some professionals showed a lack of knowledge, both theoretical and practical, about the assistance needed for this type of care. In addition to the lack of knowledge on the part of some; others showed a strong sensitivity in relation to the theme. Despite knowing that death is present in the daily lives of these nursing professionals, many do not consider themselves prepared for this moment.
\end{abstract}

Keywords: Palliative care; Nursing; Licensed practical nurses; Terminally Ill.

\section{Resumen}

Objetivo: analizar el desempeño de la Enfermería en el contexto de los Cuidados Paliativos. Metodología: se trata de un estudio observacional, transversal, con abordaje cualitativo, realizado en el contexto de la atención secundaria de salud, en una Unidad de Atención de Emergencias de una ciudad del Medio Oeste de São Paulo. La recolección de datos tuvo lugar en el primer semestre de 2020, a través de una entrevista con un instrumento elaborado por los autores, compuesto por preguntas para la caracterización de los participantes y sobre la percepción sobre la asistencia en cuidados paliativos. Los datos recolectados fueron analizados mediante análisis de contenido, modalidad temática categórica. Resultados: participaron 12 profesionales de enfermería de nivel medio, con una edad promedio de 33 años, en su mayoría mujeres (91,7\%). Se eligieron tres categorías: 1. Formación en cuidados paliativos; 2 - Conocimientos 
sobre cuidados paliativos; 3 - Desempeño en cuidados paliativos. Consideraciones finales: el presente estudio permitió comprender la dificultad que encuentran los profesionales de enfermería ante el tema de los cuidados paliativos. Algunos profesionales mostraron un desconocimiento, tanto teórico como práctico, sobre la asistencia necesaria para este tipo de cuidados. Además del desconocimiento por parte de algunos; otros mostraron una fuerte sensibilidad en relación al tema. A pesar de saber que la muerte está presente en el día a día de estos profesionales de enfermería, muchos no se consideran preparados para este momento.

Palabras clave: Cuidados paliativos; Enfermería; Enfermeros no diplomados; Enfermo terminal.

\section{Introdução}

Cuidados paliativos são cuidados ativos e integrais aos pacientes com doenças crônicas, quando estes não demostram sinais de melhora no tratamento curativo. A hipótese de que não existe nada mais a ser feito por um paciente que já não tem uma possibilidade de cura é equivocada. (Santos, Carvalho, Fonseca \& Silva, 2017).

A filosofia dos direitos humanos, como também os cuidados paliativos, baseia-se nos princípios da dignidade da pessoa, da universalidade e na ausência do preconceito. A Carta dos Direitos Humanos cita, de uma forma bem clara, a questão de respeitar o direito à saúde, favorecendo a igualdade de acesso as todas as pessoas para tratamentos, serviços preventivos, curativos ou paliativos (Capelas, Silva, Alvarenga, \& Coelho, 2016).

Os cuidados paliativos tem como princípios: validar o quanto a vida é importante, mas também de considerar que a morte é um processo totalmente natural do ciclo da vida, determinar um cuidado cujo sentido não seja acelerar hora da morte, nem a estender com ações desproporcionais (persistência terapêutica); proporcionar alivio da dor como também outros sintomas, agregar aspectos psicológicos e espirituais sabendo da sua importância na estratégia do cuidado, não esquecer da importância do apoio aos familiares no sentido de que eles possam enfrentar esse momento e prepara-los para o momento do luto (Santos, Carvalho, Fonseca \& Silva, 2017).

São destinados a pacientes de qualquer idade, seja adulto ou criança, que sofrem de algum tipo de doença onde o tratamento curativo não foi alcançado, levando a cronificação dessa patologia. A partir desse momento, a assistência prestada será totalmente direcionada para o alívio da dor e do sofrimento desses pacientes, com apoio psicológico, social e espiritual que se estende a seus familiares (Avanci, Carolindo, Góes, \& Cruz Netto, 2009; Tomaszewski, Oliveira, Arrieira, Cardosos, \& Sartor, 2017).

Enquanto filosofia assistencial, os cuidados paliativos se destinam em assistir doentes sem esperança de cura e buscar estabelecer uma forma de cuidado, tendo como conhecimento de que a morte é um processo totalmente ligado ao ciclo da vida (Paiva, Almeida Júnior, \& Damásio, 2014; Hermes \& Lamarca, 2013).

Os cuidados paliativos implicam na ação de uma equipe multiprofissional. Os desafios encontrados constantemente pelos profissionais da saúde são saber prestar um cuidado humanizado, de acordo com o grau necessidade de cada um, e fornecer orientação melhor possível à família, para que consiga lidar com o fim da vida (Hermes \& Lamarca, 2013). No Brasil ainda existe uma carência na formação dos profissionais da saúde em relação a terminalidade (Cardoso, Muniz, Schwartz, \& Arrieira, 2013).

Neste contexto, esse estudo tem por objetivo analisar a atuação de Enfermagem no contexto do Cuidado Paliativo.

\section{Metodologia}

Trata-se de um estudo observacional, transversal, de abordagem qualitativa (Pereira, Shitsuka, Parreira, \& Shitsuka, 2018), para verificar a atuação e conhecimento da enfermagem em cuidados paliativos, os sentimentos relacionados a esse assunto, facilidades e dificuldades encontradas para prestar assistência.

Este estudo foi realizado no contexto da atenção secundária a saúde, em uma Unidade de Pronto Atendimento de cidade do centro-oeste paulista. Foram convidados a participar profissionais de enfermagem que atuam na referida unidade, por haver 
contato direto de atendimento a pacientes em cuidados paliativos, que por vezes procuram a unidade para atendimento de maiores desconfortos de saúde, quando não se encontram internados.

Optou-se por um modelo de amostragem não probabilística por conveniência, de forma que o tamanho da amostra será definido pela aceitação para participar da mesma. A coleta dos dados ocorreu no primeiro semestre de 2020, em dias e horários previamente acordados com a direção da instituição, de forma a possibilitar local adequado e privativo para abordagem aos participantes.

$\mathrm{Na}$ abordagem aos integrantes da equipe de Enfermagem, houve o convite a participação e explicação do tema do estudo e objetivos do mesmo, e solicitado autorização para utilização de gravador de voz durante a entrevista. Após o entendimento por parte dos mesmos, foi entregue o Termo de Consentimento Livre e Esclarecido, que foi lido e assinado em duas vias pelo participante da pesquisa e pelos pesquisadores, entregando uma via para cada um.

Para a coleta dos dados, por meio de entrevista, foi utilizado um instrumento, elaborado pelos autores, composto por questões para caracterização dos participantes e sobre a percepção quanto ao atendimento em cuidados paliativos.

Os dados coletados foram analisados utilizando análise de conteúdo, modalidade temático categorial (Bardin, 2011).

O projeto de pesquisa foi submetido ao Comitê de Ética em Pesquisa da Fundação Educacional do Município de Assis, CAAE: 26176119.9.0000.8547, e foi aprovado com Parecer n. ${ }^{\circ} 3.735 .817$, de 29 de novembro de 2019.

\section{Resultados}

Participaram deste estudo 12 profissionais de nível médio em Enfermagem. A maioria do sexo feminino, com cor de pele branca, média de 33 anos de idade. Informações sobre a caracterização dos participantes estão disponíveis na Tabela 1.

Tabela 1. Caracterização dos participantes ( $\mathrm{n}=12)$. Assis, SP, 2021.

\begin{tabular}{|c|c|c|}
\hline Característica & Nível & n (\%) \\
\hline \multicolumn{3}{|l|}{ Sexo } \\
\hline & Feminino & $11(91,7)$ \\
\hline & Masculino & $1(8,3)$ \\
\hline \multicolumn{3}{|l|}{ Orientação sexual } \\
\hline & Heterossexual & $11(91,7)$ \\
\hline & Bissexual & $1(8,3)$ \\
\hline \multicolumn{3}{|l|}{ Estado civil } \\
\hline & Solteiro & $6(50,0)$ \\
\hline & Casado & $3(25,0)$ \\
\hline & Divorciado & $2(6,7)$ \\
\hline & União estável & $1(8,3)$ \\
\hline \multicolumn{3}{|l|}{ Cor de pele } \\
\hline & Branca & $7(58,3)$ \\
\hline & Parda & $4(33,3)$ \\
\hline & Preta & $1(8,3)$ \\
\hline \multicolumn{3}{|l|}{ Filhos } \\
\hline & Sim & $7(58,3)$ \\
\hline & Não & $5(41,7)$ \\
\hline \multicolumn{3}{|l|}{ Tempo de formação } \\
\hline & 1 a 5 anos & $6(50,0)$ \\
\hline & 6 a 10 anos & $2(16,7)$ \\
\hline & 10 a 19 anos & $4(33,3)$ \\
\hline
\end{tabular}

Fonte: Autores.

Sobre os cuidados paliativos, os dados foram organizados em categorias, que são apresentadas a seguir. 


\subsection{A formação em cuidados paliativos}

A maioria dos participantes afirmou um distanciamento, e até mesmo a falta de contato com a temática dos cuidados paliativos em sua formação. As falas que descrevem esta situação são apresentadas a seguir:

"Teve pouca coisa sobre esse tema, eu tive mais quando fiz o curso de especialização em oncologia, só eu me aprofundei mais" (E1).

"Não tive um contato direto que fosse específico para esse tema, passei a conhecer melhor aqui no meu ambiente de trabalho" (E6).

"No meu curso não tive um contato tão aprofundado com esse tema que eu me lembre, mas aqui por ter bastante internação sobre esse tipo de caso vamos aprendendo cada dia um pouco mais" (E7).

"Não consigo lembrar no momento se no meu curso foi falado sobre esse tipo de cuidado, mas passei a aprender aqui no ambiente de trabalho, na assistência porque aqui a gente aprende bastante” (E11).

Contudo, houve um participante que afirmou uma formação simplicista nessa temática.

"O que eu vi mais foi que existia os cuidados paliativo, tive um conceito básico sobre esse tema" (E12).

Entretanto, uma participante, por ter realizado curso de especialização em oncologia, afirma que já participou de eventos dessa natureza.

"Sim, já participei, no curso de especialização" (E1).

\subsection{O conhecimento sobre cuidados paliativos}

Quase todos os entrevistados afirmaram que cuidado paliativo é se preocupar com o conforto e o bem-estar do paciente nos seus momentos finais da vida, conforme as falas a seguir.

"Cuidados paliativos eu acho que é tudo que você pode fazer pelo bem-estar do paciente, no fim da vida dele, é você cuidar desse paciente e ter atenção com a família, você dá uma qualidade de vida pra ele, no fim da vida" (E1).

"Pra mim cuidados paliativos é oferecer um final de vida menos doloroso, porque são cuidados que a gente dá para que a pessoa tenha um fim menos sofrido" (E4).

"Cuidados paliativos são os cuidados que realizados a pessoas que tem uma determinada patologia que não tem mais cura, então esses cuidados servem para trazer um conforto e paz nos seus últimos dias de vida" (E8).

"Cuidados paliativos é forma de prestar um conforto ao paciente que está em fase terminal, é um cuidado primordial na vida desse paciente" (E11).

Para todos os entrevistados, os cuidados paliativos são destinados a pacientes em estado terminal.

"Aos pacientes mais em fases terminais, com câncer, que tem doenças crônicas, pacientes mais acamados, o Alzheimer até eu acho que ele se enquadra um pouco também" (E1).

"Pra mim são pacientes em fase terminal que não respondem mais ao tratamento, e não alcançam mais a cura" (E5).

"A pacientes acamados, que não tem uma boa qualidade de vida, que tem a mobilidade prejudicada, pacientes em fase 
terminal, é voltado a um público dependente" (E10).

"Pacientes em estado terminal como o câncer, por exemplo, ou pacientes com doenças crônicas como o DPOC, AVC, pacientes acamados, acredito que seja isso" (E11).

"Pacientes que não tem mais possibilidade de recuperar, de estabelecer a saúde né, um paciente que ele está indo a caminho praticamente do óbito, porque ele não tem mais condições de reestabelecer a saúde dele" (E12).

Sobre a importância dos cuidados paliativos, os entrevistados afirmaram ser de extrema importância, às vezes, indispensável, no cuidado com o paciente:

"Pra mim como eu disse é superimportante, pois o fato de você está ali oferecendo os cuidados mesmo sabendo que a qualquer momento essa pessoa vai partir, mas você está dando o seu melhor pra ele descanse de forma digna e dá melhor maneira possivel" (E3).

"Eu acho muito importante porque eu acredito que todo mundo merece morrer de um jeito digno, ninguém merece ficar sofrendo sendo que pode ser amenizada a dor e o sofrimento, então é importante" (E4).

"É importante sim porque podemos oferecer uma assistência da melhor maneira possível pra pelo menos tentar amenizar o sofrimento desses pacientes terminais, promover dignidade, conforto até o último dia de vida da pessoa" (E5).

"É importante pelo conforto que oferecemos tanto pelo paciente como para a família, trazendo até mesmo alívio dos sintomas que ele apresenta" (E8).

"Em minha opinião não é só importante como indispensável, por saber que pode trazer dignidade e respeito pelo ser humano nessa situação, acredito que é importante tanto para o paciente como para a família” (E9).

Na dimensão biológica, quando indagados sobre os sinais e sintomas mais prevalentes em cuidados paliativos, a grande maioria citou a dor como a principal queixa:

"A dor né, o estado geral do paciente né, nutrição, tudo, eu acho que você observando bem consegue melhorar bastante" (E1).

"Dor, mal-estar né eu acredito que seja isso né aquelas náuseas que não passam e o pior é a dor né" (E2).

"Eu acredito assim pelo que eu vejo os sinais que mais prevalecem é a dor e que consequentemente acaba levando ao sofrimento, a angústia de estar passando por isso, e muitos pensam que parece nunca vai acabar" (E3).

"Para mim os sinais e sintomas que são bem visiveis são a dor que muitas vezes pode levar a vários outros como a hipertensão, taquicardia, desconforto respiratório, a tristeza porque essa situação que ele está vivendo não é fácil, o sofrimento, esses não os sintomas que mais se mostram presentes" (E11).

Já dimensão psicológica, quando indagados sobre os sinais e sintomas mais prevalentes em cuidados paliativos, a grande maioria citou a depressão como principal sintoma:

"Na parte psicológica eu vejo que eles ficam muito abalados pela situação em que estão vivendo, não somente o paciente como também a família dele, acaba gerando muita dor e angústia pra todos que estão ali vivendo e vendo todo esse sofrimento" (E3).

"Eu acho que tem alguns que ficam muito depressivos porque sabem do que estão passando, sofrem com o sofrimento 
da família e às vezes se sentem um fardo, e pensam nas pessoas achando que elas cuidam deles por obrigação, perdem o sentido da vida" (E5).

"Medo, angústia, não tem perspectiva do futuro porque não pode mais planejar o amanhã, consequentemente entra a ansiedade de saber como vai ser o seu próximo dia, é isso parte psicológica é a que fica mais comprometida" (E9).

"Eu acredito que o psicológico desses pacientes fica totalmente vulnerável, sentem muita angústia, depressão, falta de esperança e solidão, outros acredito que encaram toda essa situação com determinação e esperança" (E11).

Sobre a dimensão social, quando indagados sobre os sinais e sintomas mais prevalentes em cuidados paliativos, alguns citaram o abandono:

"Eu vendo, eu acho que já tem um abandono e preconceito, por exemplo, você já vê a pessoa com um lenço na cabeça as pessoas se afastam um pouco, eu acho que a sociedade é um pouco preconceituosa quanto a isso e a gente teria que fazer alguma coisa pra eles não serem assim, mas eu acho que é do ser humano" (E2).

"Eu acho que a sociedade não é preparada pra cuidar desses tipos de pacientes, as pessoas são muito egoístas, elas gostam de ser cuidadas, mas na hora de cuidar muita gente não cuida, eu acho que é por isso que tem tanto idoso no asilo, porque tipo assim a mãe cuida de quantos filhos tiver, e os filhos já levam para o asilo e deixam lá e abandonam, então eu entendo que o sintoma que mais prevalece é o abandono" (E4).

"Na parte social para mim eu acredito que seja esse distanciamento dos familiares com o paciente por esse medo de não saber o que fazer, muitas vezes acreditam que estando aqui já está ótimo e que não precisa se preocupar, sendo que a melhor forma de cuidado que ele precisa é do amor da familia nesse momento” (E7).

Por outro lado, houve entrevistados que perceberam uma aproximação entre os pacientes e seus familiares:

"No caso do convivio eu penso na familia no caso, eu acho que a família se interage mais com a própria doença da pessoa, eu acho que fica mais unido, ainda mais porque o foco seria mais todo mundo tá junto, sofre todo mundo, ou afasta totalmente que é o mais triste" (E1).

"Eu acredito que isso depende da cabeça de cada um, porque cada um tem uma opinião, tem gente que acha que atrapalha, algumas famílias às vezes veem que a gente vai prestar o cuidado e preferem que a gente não fique manipulando o paciente pra deixa-lo tranquilo, às vezes pensam que a gente deve estar judiando do paciente" (E5).

"Eu penso que por esse paciente estar nessa situação todos que tem um certo vínculo com ele sofre também né, os familiares, amigos, e assim eu acredito que essa é uma fase que passa a existir a aproximação, porque as vezes tem muito conflito na família e quando a família descobre que esse paciente está em fase terminal eles buscam a mudança, as pazes e a melhor forma de convívio" (E6).

Enquanto outros perceberam sinais tanto positivos, quanto negativos, aqueles que as famílias apoiam, e aqueles que estão sozinhos:

"Na parte social eu vejo de tudo, tanto aqueles que a família está ali sempre presente, abraçando, cuidando no último momento, se doando pelo seu familiar, como também aquele que muitas das vezes prefere ficar longe pra não ter que sofrer junto, e eu penso assim não é que eles não se importam, mas preferem apenas ficar apenas com boas lembranças daquela pessoa e de quanto ela foi importante tanto pra ela como pra todos" (E3). 
"Aqui no meu serviço eu consegui observar que alguns tinham comunicação com a familia, eram muito bem cuidados e cercados de carinho sabe, e outros que eu pude observar também que as vezes não estava com ninguém da família mas sempre teve alguém tipo um conhecido, um vizinho, alguém que veio pra ajudar a prestar esse cuidado naquele momento, não percebi nenhum desassistido não" (E12).

Sobre a dimensão espiritual, a maioria dos entrevistados disse que um dos sinais e sintomas mais prevalecente é a fé:

"Eu acho que aquele que tem mais fé fica mais fácil, agora aquele um que não tem fé, que é uma pessoa assim que quando você vê tá sempre reclamando, ai eu acho que é mais difícil, tem mais sofrimento... quando você aceita, quando você tem fé, você tá se apegando em uma coisa que você crê então assim é uma força a mais, saber que o seu sofrimento é temporário e que vai passar, aquele é um caminho você tem que passar por aquilo, mas lá na frente você não vai mais ter esse sofrimento" (E1).

"Eu acho que quem tem fé aceita melhor, agora tem aquele que acha que Deus tá cobrando alguma coisa dele, que sempre fala o que eu fiz de errado? Por que Deus tá fazendo isso comigo? Deus não é justo com as pessoas fazendo isso? E é assim eu acredito que tem fé passa por esse momento melhor pelo lado espiritual, aquele já que não acredita acha que Deus tá cobrando alguma coisa dele, fala que Deus é responsável por aquilo.., mas não é” (E2).

"Sempre tem alguns que tem um grau de espiritualidade mais elevado, tem sempre aquele que acredita que vai acontecer o milagre, que acredita que o melhor médico é Deus, e assim a gente respeita muito ... sempre é falado com sinceridade, não querendo abalar a fé dessa pessoa, mas já preparando para o que pode acontecer" (E7).

"Como disse muitas vezes a fé é o melhor alicerce para essa pessoa, e ela busca a Deus com tudo que ela tem, para mim acreditar em Deus ajuda sim, mas não podemos acreditar que ele vai fazer só o que a gente quer mas a vontade dele também, para mim pacientes que demonstram não ter fé sofrem mais e acabam descontando seu sofrimento em quem não merece. É dificill" (E11).

Da mesma forma que alguns perceberam a fé de forma positiva, teve quem percebeu de forma negativa, como se estivesse questionando a existência de Deus:

"Eu acho que a pessoa fica mais resmungona, porque abala a fé, e abalando a fé abala todos os conceitos da pessoa porque é onde a pessoa fica destruída e acaba discutindo com Deus, se revoltando contra Ele e pensa que ele serviu a Ele a vida toda para terminar nessa situação" (E9).

"Eu penso assim, as pessoas muitas vezes não são tão apegadas a Deus, ou não se preocupa, ou não vai atrás, e quando bate uma situação dessas que é caótica acaba querendo se apegar a Deus, de princípio não tem aquela aceitação, mas depois busca ajuda em Deus, e eu penso que não deveria ser assim, para mim Deus é tudo, e deveria fazer parte de tudo na vida não só dos momentos ruins seja a dor e o sofrimento" (E10).

Outros perceberam que a fé deve ser respeitada, independente de qual seja:

"Ai eu acho que é muito individual a parte espiritual, religiosa, eu acredito que tem que ser respeitado independente de qual for, e de quem for seja uma pessoa jovem ou uma pessoa idosa, cada uma precisa ter o seu espaço" (E4).

"No espiritual depende de cada pessoa, porque eu já vi casos de pessoas tentarem falar de Deus para eles e acabarem não aceitando talvez porque já tinha sua religião específica e outros porque não tem nenhuma religião, então referente 
a isso eu prefiro não mexer" (E8).

\subsection{A atuação no atendimento em cuidados paliativos}

Todos os entrevistados já realizaram atendimento de cuidados paliativos, para alguns, a experiência boa:

"Eu acho que como a gente tá sempre aqui né acaba sendo rotineiro" (E1).

“Já realizei, foi bom pelo conforto que eu ofereci ao paciente, eu sai satisfeita pelo que eu fiz" (E2).

"Já realizei sim, e assim eu me considero uma pessoa muito humana... eu já cuidei bastante de pessoas assim, e eu sinto que eu saio fortalecida" (E10).

E, para a grande maioria, a experiência foi negativa:

"Já sim, já recebemos vários pacientes em cuidados paliativos, pra mim é uma experiência triste porque é ruim vê a pessoa naquela situação e saber que a qualquer momento ela vai partir e isso dá uma tristeza na gente, e as vezes a gente pensa porque que não parti logo de uma vez de tudo isso, e a gente pensa na família sentindo pena do sofrimento deles também que vão sofrer com essa perda" (E5).

“... sempre vai ser uma experiência triste” (E6).

"Sim, como eu disse surgem bastantes casos aqui na unidade, a experiência para mim como pessoa, ser humano, não é boa, vê que o paciente está naquela situação decadente" (E7).

"Sim já realizei, eu acho uma situação muito sofrida, eu acho muito difícil cuidar" (E8).

"Sim, não é uma experiência boa, creio que pra ninguém é um paciente que você sabe que está prestando a assistência apenas para um alivio e não para resolução do problema” (E9).

A maioria percebeu necessidade de melhoria no que diz respeito à comunicação, e à própria atuação:

"Eu acho que tem que melhorar bastante, eu acho que a gente é muito técnico, e acaba assim sendo" (E1).

"Eu acredito que a gente tem sempre a melhorar, mas sim o contato, o cuidado eu acredito que eu me avalio bem, consigo me comunicar, oferecer o meu melhor" (E2).

"Para mim é um pouco complicado essa situação, porque muitas vezes a gente acaba se expressando de forma errada, dizendo que vai ficar tudo bem e nessa fala você acaba dando esperanças ao paciente e aos familiares" (E6).

Enquanto esses entrevistados são mais abertos, tendo maior facilidade para conversar com os pacientes:

"Com o paciente a gente tenta explicar o máximo que o que a gente está fazendo por ele é o melhor pra ele nesse momento, e eles até aceitam e entendem, porém lidar com a família é mais difícil, chega a ser mais difícil do que com a paciente" (E3).

"Eu geralmente, no meu ver como profissional, eu sou uma pessoa bem amiga, mas eu também sou verdadeira, eu gosto deixar o paciente a par de tudo que está acontecendo, gosto de ser sincera e verdadeira com o que está se passando, por ficar enganando o paciente não é bom para ele" (E9).

"Eu me considero uma pessoa bem aberta, converso bastante, sou uma pessoa que pensa muito positivo, e muitas vezes os pacientes ou acompanhantes falarem que eu sou diferente, que eu me comunico e que me faço presente, e isso é 
muito difícil não são todos que tem atitudes como as minhas" (E10).

Já esse entrevistado prefere deixar essa parte da comunicação para a equipe médica ou para os enfermeiros:

"Essa parte eu prefiro não fazer, não tenho muito jeito ou dom pra conversar sobre isso, acho que isso é responsabilidade do médico, da enfermeira, eles conversam e explicam porque tem muita gente que é difícil de aceitar a situação" (E4).

Quando abordados sobre a atuação no controle de sintomas que pessoas em cuidados paliativos apresentam, e como avaliam sua atuação, a maior parte dos entrevistados percebe a dor como primeiro sinal, e que deve ser tratado quase que imediatamente:

"Eu penso assim que quando a pessoa está com dor ou apresentando alguma alteração fisiológica a gente precisa comunicar o médico administrar as medicações necessárias que ele prescrever” (E5).

"Eu acredito muito que o sintoma que mais surge é a dor, e eu buscaria as medicações de forma rápida" (E6).

"Eu vejo muito a expressão facial, como uma expressão de dor, um gesto de mão, às vezes vejo que a posição que ele se encontra pode estar incomodando o paciente, e se avaliando eu vejo que é dor corro atrás de medicação, se for a posição, tento mudar o decúbito para melhorar o desconforto, nessa parte eu consigo me manifestar com alguma atitude" (E8).

Quando perguntados sobre a atuação na prestação de apoio à família de pessoa em cuidados paliativos, há quem perceba que essa parte é um pouco falha, havendo falta de tempo:

"Vou pensar aqui né, aqui é bem falho a gente não tem tempo né, pela correria e é muita gente, a gente pode até conversar mais é uma conversa muito rápida, não é aquela conversa esclarecedora, o tempo que você tem não te deixa esclarecer que às vezes eles querem tirar dúvidas sobre o que pode fazer, o que pode deixar de fazer, assim o tempo é muito corrido" (E1).

Há aquele que não sabe como agir nesse momento, pedindo auxílio para o enfermeiro:

"Então é isso que comentei, essa parte eu não consigo fazer, um apoio profissional eu consigo oferecer, mas emocional que a família está precisando, mas eu passaria para a enfermeira tomar a atitude correta nesse momento" (E8).

A maioria dos entrevistados percebeu que a atenção deve ser dada tanto à família quanto ao paciente:

"Eu acho que além do doente que precisa dessa atenção a família ali é o principal porque eles precisam ficar ali do lado e depois ainda passar pelo luto" (E2).

"Lidar com a família pra mim não é tão fácil, mas sempre que necessário tento dar uma palavra de conforto a eles pra tentar minimizar o sofrimento no qual eles estão passando. Um ambiente adequado para estar conversando com a família seria muito bom" (E3).

“Eu converso bastante, eu oriento sobre tudo que é necessário fazer pelo paciente da maneira mais fácil e uma técnica 
mais correta, eu tento passar o meu conhecimento para se seja mais fácil a adaptação dele para que eles possam oferecer conforto ao paciente em casa" (E9).

Entretanto, alguns entrevistados procuram ajuda em Deus e repassam isso aos pacientes:

“... busco dar o apoio tanto nos cuidados, quanto no emocional, mas claro que sem dá esperanças que não existem, acredito que às vezes uma palavra de Deus ajuda, um abraço, um aperto de mão, isso já faz uma grande diferença na vida deles" (E6).

“... eu sou uma pessoa muito apegada a Deus e eu acho que tudo tem um propósito na vida, então eu tentaria passar para a família entender que o sofrimento não é o melhor para esse paciente no momento, às vezes até o paciente não quer ver a família dele sofrendo nesse momento” (E10).

Em sua opinião, quais os fatores que facilitam o atendimento em cuidados paliativos?

“Eu acredito que medicação sempre e é o que tem sempre” (E2).

"Pra mim o que facilita é ter o médico aqui sempre pra tirar nossas dúvidas, pra estar conversando com a família tirando as dúvidas deles também, graças a Deus medicações pra ele tipo de atendimento sempre tem, analgésicos que é o principal no que se diz respeito ao alívio da dor” (E3).

"Pra mim o que facilita é a união da equipe para prestar uma boa assistência, quando temos uma boa comunicação o trabalho fica ótimo” (E4).

“Não sei dizer o que facilitam, para mim esse lugar não é indicado para esses tipos de pacientes” (E6).

“A informação, estar sempre atento a tudo que está acontecendo, e facilita em ter os recursos para atuar corretamente diante dos problemas" (E7).

“O que facilita é que no meu ver os meus colegas são bem unidos, então um ajuda o outro nos cuidados, facilita também a presença de um acompanhante porque traz mais conforto para o paciente, as medicações de alívio que graças a Deus sempre tem” (E9).

“Acredito que as medicações são o que facilitam porque aqui trabalhamos com medicações padronizadas” (E12).

E quais os fatores que dificultam esse atendimento?

"Dificulta porque aqui é um pronto atendimento, então não seria um local adequado, em questão de infraestrutura, a gente não tem um leito que tem biombo...” (E1).

"Como citei antes, acredito que o que acaba dificultando é o local, pois não oferece a estes pacientes um ambiente calmo e tranquilo que seria necessário diante deste momento que estão vivendo, um local adequado seria muito importante e necessário” (E3).

"O que dificulta é o fato de não ter onde colocar esses pacientes, deveria ter um lugar especifico que não seja aqui e que tenha uma estrutura adequada para recebê-los e aqui não seria um local adequado pra isso” (E5).

"O que dificulta é a nossa correria diária no atendimento dos pacientes, porque na maioria das vezes a o tempo é bem curto e são muitas internações" (E9). 


\section{Discussão}

A formação em cuidados paliativos, conforme os resultados obtidos nas entrevistas, é deficitária. A grande maioria 11 $(91,7 \%)$ afirmaram que a temática de cuidados paliativos não foi abordada em sua formação.

Essa realidade também é encontrada nas Unidades de Internação e Ambulatório Hospitalar de quimioterapia, em duas capitais do Sul do País onde os profissionais entrevistados relatam uma certa falha na formação profissional e na educação permanente, que acaba impossibilitando o desenvolvimento desta habilidade com êxito. (Luz, Vargas, Barlem, Schmitt, Ramos, \& Meirelles. 2016).

No que se diz respeito à formação profissional na temática de cuidados paliativos, deve-se estimular, cada vez mais, o ensino teórico e prático dos cuidados paliativos, e incentivar pesquisas com objetivo de melhorar esta formação (Costa, Poles, \& Silva, 2016).

Ressalta-se a necessidade de maior número de publicações sobre cuidados paliativos, a fim de que a comunidade acadêmica amplie seus conhecimentos, visto a importância da presença do enfermeiro e de profissionais especializados na área. Desta forma, novos estudos se fazem necessários, como treinamentos por parte dos serviços de saúde, buscando uma melhoria no sistema desses cuidados (Markus, Betiolli, Souza, Marques, \& Migoto, 2017).

Em relação ao conhecimento em cuidados paliativos, os resultados obtidos nas entrevistas são considerados significativos. A grande maioria 11 (91,7\%) afirmou que esse tipo de cuidado consiste em oferecer o alívio da dor e do sofrimento ao paciente que se encontra no estado terminal de vida garantindo ao mesmo conforto e dignidade. Contudo, um entrevistado $1(8,3 \%)$ considera esse tipo de assistência como um cuidado qualquer.

Entretanto esta realidade é totalmente contrária a um Hospital do Interior de Pernambuco/PE que mostrou através de uma pesquisa um conhecimento insatisfatório da parte dos profissionais de enfermagem relacionado ao tema de cuidados paliativos (Santiago, Alves, Freire, \& Korinfsky, 2017).

Em relação ao conceito de cuidados paliativos, dentro do que a Organização Mundial da Saúde define, apenas 1(8,3\%) entre os profissionais entrevistados pode afirmar que já realizou a busca neste site e pode confirmar a existência desse conceito, enquanto que 11(91,7\%) dos entrevistados relataram não ter contato com este site ou já ter visto algum conceito sobre este tema.

O conceito atual da OMS amplia o horizonte de ação dos cuidados paliativos, podendo ser adaptado às realidades locais, aos recursos disponíveis e ao perfil epidemiológico dos grupos a serem atendidos: Cuidados Paliativos são uma abordagem para melhoria da qualidade de vida de pacientes e familiares que enfrentem uma doença ameaçadora da vida, através da prevenção e do alívio do sofrimento, através da identificação precoce e impecável avaliação e tratamento da dor e outros problemas, físicos, psicossociais e espirituais (Gomes \& Othero, 2016).

Na realidade do Hospital das Clínicas de Porto Alegre/RS que é uma unidade de internação voltada a pacientes que necessitam de cuidados paliativos onde diante da organização de um núcleo estabelece essas internações admiravelmente, e para eles o conceito de Cuidados Paliativos realmente é importante vindo da definição dada pela OMS sabendo que os cuidados paliativos são preconizados por organismos internacionais, como Organização Mundial da Saúde e a United Nations Educational, Scientificand Cultural Organization (UNESCO), resultando na estruturação de uma rede de atenção à saúde que é incipiente em nosso pais, especialmente pelas classes menos favorecidas economicamente (Kruse, Vieira, Ambrosini, Niemeyer, \& Silva, 2007).

No que se diz respeito a importância dos cuidados paliativos, todos os entrevistados 12 (100\%) declararam não somente ser de extrema importância, como muitas das vezes indispensável, no cuidado com o paciente em seus últimos momentos de vida.

Os cuidados paliativos são sim muito importantes para a assistência aos pacientes paliativos, são formas de demonstrar tanto para o paciente como para a família que ele como todo ser humano merece dignidade desde o início até o fim de sua vida. 
Esta realidade tem sido presente no Hospital Escola no Rio Grande do Sul seus profissionais tem o conhecimento de que as necessidades dos pacientes devem ser atendidas, e o cuidado deve ser integral, e é consideravelmente primordial não somente para toda a equipe de saúde como para os pacientes, e que todos devem resgatar um a relação interpessoal empática, sendo fundamental ouvir e tornar-se sensível às necessidades dos pacientes pois estes pacientes esperam que a relação com os profissionais da saúde seja alicerçada por compaixão, respeito e empatia, de modo a auxiliá-los no processo de morte, valorizando a sua experiência. (Cardoso, Muniz, Schwartz, \& Arrieira, 2013).

A Enfermagem possui o papel de importante profissional responsável por humanizar a assistência, pois como enfermeiro, sua visão deve estar atenta as reais necessidades que o paciente apresenta, podendo identificá-las rapidamente, seja de forma verbal, ou não verbal, e suprindo-as da melhor maneira possível, e quando não lhe couber, tendo voz e auxílio de uma equipe multiprofissional. Porém para que isto aconteça, é necessário que o profissional entenda o motivo de se executar Cuidados Paliativos, bem como os seus princípios, que são aquilo que os diferencia de uma assistência comum, intervencionista, curativa (Franco, Stigar, Souza, \& Burci, 2017).

Com relação ao fato de os cuidados paliativos ajudarem ou atrapalharem, todos os participantes $12(100 \%)$ afirmaram que ajudam:

Acredito que de fato sim ajudam e muito, tanto o paciente como os familiares que estão presentes neste momento de dificuldade e sofrimento.

Voltado a esta indagação vemos a realidade na Unidade hospitalar de cuidados paliativos no município de São Paulo/SP, onde os profissionais reconhecem que todos os seres humanos têm o direito de cuidar-se e de serem cuidados. Ainda afirmam que este trabalho é uma experiência única, um campo de trabalho que enriquece a cada dia. "É um trabalho difícil, mas que dá ânimo para levantar todo dia de manhã. Trabalhar em cuidados paliativos representa realização, prazer, atuação. É o que me representa como um bom profissional" (Silveira, Ciampone, \& Gutierrez, 2014).

Os cuidados paliativos podem e devem ser oferecidos concomitantemente aos cuidados curativos, pois não são excludentes para a prevenção e tratamento do sofrimento do paciente e seus familiares. Portanto, é errônea a suposição de que "não há mais nada a se fazer" pelo paciente sem possibilidades de cura: enquanto houver vida, sempre existirá a necessidade do cuidado de enfermagem. Enquanto existe vida, há muito que se fazer para a pessoa transpor os últimos dias de sua existência sem sofrimento. Resultando assim num posicionamento totalmente positivo quanto aos cuidados paliativos (Freitas \& Pereira, 2013).

Na dimensão biológica, quando indagados sobre os sinais e sintomas mais prevalentes em cuidados paliativos, a grande maioria citou a dor como a principal queixa.

Acredito sim que a dor é um sintoma bem presente nestes tipos de pacientes e que ela deve ser observada e amenizada, pois isso garante conforto ao paciente.

Esta realidade também é defendida pelas profissionais do Hospital e Maternidade Celso Pierro em Campinas/SP onde as profissionais relatam que podem observar que os cuidados paliativos são aqueles que amenizam a dor e proporcionam conforto ao paciente em fase terminal da vida. (Freitas \& Pereira, 2013).

Também é uma realidade encontrada em uma unidade Clínica de Internação de um Hospital de ensino no Sul do Brasil onde os profissionais afirmam que o tratamento da dor também pode evitar náuseas. É aquele cuidado que não vai reverter o quadro, não vai prolongar a vida, mas que vai dar conforto para esse paciente como para sua família. (Cardoso, Muniz, Schwartz, \& Arrieira, 2013).

Já dimensão psicológica, quando indagados sobre os sinais e sintomas mais prevalentes em cuidados paliativos, a grande maioria $9(75 \%)$ citou a depressão como principal sintoma.

Acredito que a depressão tem sido sim algo presente, pois de certa forma estes pacientes tem um conhecimento sobre 
esse momento, e seja um jovem ou um idoso se sentirá momentos de tristeza, angustia e desesperança.

A depressão acarreta diminuição da qualidade de vida e amplificação da dor, o sofrimento psicossocial é reconhecido como uma fonte de mal-estar nos doentes terminais. A depressão em pacientes de cuidados paliativos diminui consequentemente a aceitação terapêutica, levando-o ao desejo da antecipação da morte (Julião \& Barbosa, 2011).

Franco (2005) defende que, apesar da depressão ser um problema frequente, não deve ser considerada como uma parte necessária ou normal do processo de morrer, mas sim uma condição clínica tratável.

Sobre a dimensão social, quando indagados sobre os sinais e sintomas mais prevalentes em cuidados paliativos, alguns entrevistados 3(25\%) citaram o abandono. Por outro lado, houve entrevistados 4(33,3\%) que perceberam uma aproximação entre os pacientes e seus familiares.

Mesmo sendo uma fase tão difícil, o abandono realmente é presente nos cuidados paliativos, neste momento em que os pacientes mais necessitam de contato com sua família e amigos. Mas também há muitos que familiares que acompanham este momento até o fim.

No entanto esta realidade também é vista de outra forma, pois o Manual de Cuidados Paliativos ser importante ressaltar que nesta perspectiva não consideram obrigatória a presença da família ou do cuidador em todas as intervenções; em algumas situações o paciente, apesar do diagnóstico de doença incurável e já em atenção paliativa, ainda se mantém autônomo e comparece às primeiras consultas, desacompanhado (Carvalho \& Parsons, 2012).

Em situações de crise - como no caso de adoecimento e fim da vida -, são esperadas mudanças na organização familiar e, consequentemente, nos papéis desempenhados pelos familiares, o que justifica a inclusão dessas pessoas na assistência prestada pelas equipes de cuidados paliativos. Essas equipes podem ajudar tanto doentes quanto familiares a enfrentar e a aceitar a situação de fim da vida por meio de cuidado que minimize o sofrimento físico, psicossocial e espiritual (Espíndola, Quintana, Farias, \& München, 2018).

Sobre a dimensão espiritual, a maioria dos entrevistados disse que um dos sinais e sintomas mais prevalecentes é a fé.

É necessário considerar a pessoa como ser holístico para se entender a espiritualidade como um aspecto importante no processo terapêutico e essencial para o bem-estar. O profissional de saúde pode ajudar o paciente ouvindo-o, estando atento às suas emoções e aos seus sentimentos. Muitas vezes, isso é mais importante que qualquer terapêutica (Selli \& Alves, 2007; Silva, 2020).

Já na pesquisa de Arrieira et al. (2018), os profissionais da saúde mencionaram que, por meio da espiritualidade, é possível oferecer conforto aos pacientes. Também foram relatadas no depoimento a relevância e a força do pensamento positivo num exercício de transcendência, ou seja, de buscar algo fora de si, que, segundo os participantes, traz resultados benéficos.

Com relação a atuação no atendimento em cuidados paliativos todos os entrevistados já realizaram atendimento de cuidados paliativos, para alguns, a experiência foi boa, para outros se tornou rotina, mas, para a maioria a experiência foi negativa.

Assim como demonstra a pesquisa de Silveira et al. (2016) onde eles citam que o ambiente de trabalho dos profissionais de enfermagem os submete a inúmeras situações estressantes que podem estar relacionadas à atividade laboral, como também à processos psicológicos e físicos do próprio indivíduo. Essa situação limita a atuação e a concepção do profissional no momento do processo de morte e morrer.

Corroborando com os autores anteriores e com a maioria doa entrevistas da presente pesquisa Santana et al. (2009) concluem que com relação ao preparo dos profissionais em lidar com a morte, percebemos que a grande maioria tem dificuldades e não encontram um suporte adequado no ambiente de trabalho. Muitas vezes precisam utilizar de suas próprias experiências para acompanhar melhor o processo de finitude, ou seja, acabam definindo os cuidados paliativos como uma experiência negativa.

Sobre a atuação na comunicação com o paciente e a família, um entrevistado partiu para a religião, achando ser a melhor 
forma de contato, porém maioria percebeu necessidade de melhoria no que diz respeito à comunicação, e à própria atuação.

Barbosa e Silva (2007) afirmam que o enfermeiro considera a comunicação como um instrumento indispensável ao desempenho profissional, fazendo com que a informação chegue ao seu destino de forma clara evitando possíveis dúvidas, tanto no que se refere à equipe multiprofissional quanto ao paciente; garantindo assim a segurança em todos os processos da assistência.

Conforme a pesquisa de Rezende et al. (2014) a comunicação se revela essencial na assistência de enfermagem, uma vez que, quando desenvolvida de forma adequada, minimiza esses sentimentos. Como observado nos depoimentos, os familiares têm como principais necessidades: receber informações sobre o estado de saúde de seu parente e ser bem acolhido de forma digna e humanizada.

Quando abordados sobre a atuação no controle de sintomas que pessoas em cuidados paliativos apresentam, e como avaliam sua atuação, a maior parte dos entrevistados percebe a dor como primeiro sinal, e que deve ser tratado quase que imediatamente.

Conforme estudo de Sampaio, Motta e Caldas (2019) a ação de uma equipe de cuidados paliativos treinada leva ao melhor controle de sintomas e qualidade de vida dos pacientes.

Quando perguntados sobre a atuação na prestação de apoio à família de pessoa em cuidados paliativos, a maioria dos entrevistados percebeu que a atenção deve ser dada tanto à família quanto ao paciente.

O apoio e cuidados com os sentimentos da família, da equipe de saúde, e, em especial, com a equipe de psicólogos, que atuam no hospital, vêm sendo foco de atuação dos profissionais preocupados com a "qualidade de morte", assim como com a qualidade de trabalho de equipe e apoio a famílias que se encontram nesta difícil e inexorável situação existencial. Há necessidade de intervenção psicológica para com os pacientes e seus familiares envolvendo ainda todos da equipe interdisciplinar que muitas vezes não sabem lidam com a perda de seus pacientes (Oliveira, Voltarelli, Santos, \& Mastropietro, 2005).

Os familiares merecem um cuidado especial, desde o instante da comunicação do diagnóstico, uma vez que esse momento tem um enorme impacto sobre eles, que veem seu mundo desabar após a descoberta de que uma doença potencialmente fatal atingiu um dos seus membros. Trindade e colaboradores (2006); Cordeiro \& Silva, 2020).

Sobre o trabalho em equipe multidisciplinar e a sua avaliação sobre o assunto, todos os entrevistados disseram que sabem atuar de forma positiva em equipe, que há respeito, e a comunicação entre os membros da equipe é fácil.

Mais uma vez é frisado o cuidado com a saúde mental de todos da equipe multidisciplinar que atua nos cuidados paliativos, como demonstra a pesquisa de Silveira, Ciampone e Gutierrez (2014) onde os mesmos citam que para que essa equipe interprofissional consiga desenvolver seu trabalho com sucesso, torna-se imprescindível que a saúde mental de cada integrante seja mantida e aprimorada, uma vez que implica enorme ganho para os próprios profissionais envolvidos com os cuidados do indivíduo no fim da vida, e também para a qualidade desses cuidados oferecidos ao paciente e à família.

Conforme Carvalho (2006) a sensibilidade da equipe multiprofissional demonstra a humanização no processo de cuidar e a importância da integralidade do cuidado, ou seja, corrobora com os preceitos dos entrevistados dessa pesquisa, onde os mesmos citam que a comunicação e o trabalho envolvendo toda a equipe deve ser sempre positivo, visando o bem estar de todos.

Quando indagados quanto quais os fatores que facilitam o atendimento em cuidados paliativos, alguns dos entrevistados citam a medicação que o paciente toma, outros a comunicação com a equipe médica e de enfermagem, e a maioria o bom entrosamento entre a equipe multidisciplinar.

O trabalho de cada profissional dentro da equipe multiprofissional é aprendido como um conjunto de atribuições, atividades ou tarefas. Mas uma vez que existem profissionais de diferentes áreas, que atuam juntos - cada um com um conhecimento específico (Zombini, Bogus, Pereira, \& Pelicioni, 2012).

A satisfação no trabalho está diretamente relacionada ao estado emocional e prazeroso, ou seja, o resultado das experiências no ambiente profissional, quando positivo, satisfaz o trabalhador (Silva, 2012). 
Posteriormente foram indagados quanto quais os fatores que dificultam o atendimento em cuidados paliativos e todos os entrevistados citaram o local onde os pacientes estão como um agente dificultador para os cuidados paliativos, pois são expostos muitas vezes à muitas pessoas e barulhos.

De acordo com a pesquisa de Oliveira, Maranhão e Barroso (2017) os resultados permitiram identificar a necessidade de estimular os profissionais a pesquisarem a respeito dessa temática, tornando-se necessário aos profissionais serem mais ativos na produção de conhecimento e de bases científicas para uma atuação mais efetiva diante dos paciente e familiares que necessitam de cuidado diante da progressão da doença e aproximação da morte. Onde conforme exposto na presente pesquisa, também se mostrou evidente o que pó de acarretar a dificuldade quando a adaptação à diferentes locais em que os pacientes estejam alojados.

\section{Considerações Finais}

O presente estudo possibilitou compreender a dificuldade que os profissionais de enfermagem encontram diante da temática de cuidados paliativos. Alguns profissionais mostraram certa falta de conhecimento tanto teórico quanto prático sobre a assistência necessária para esse tipo de cuidado. Além da falta de conhecimento por parte de alguns; outros apresentaram uma forte sensibilidade em relação a temática. Apesar de saber que a morte se faz presente no dia-a-dia desses profissionais de enfermagem, muitos não se consideram preparados para este momento. Também pode ser observado que os profissionais que possuem um período maior de experiência se mostraram mais equilibrados diante desses momentos.

Quando se fala do contexto de cuidados paliativos em alguns artigos pode-se observar como os autores acabam referindo sobre esses cuidados serem belos no meio profissional, no entanto poucos argumentam sobre as dificuldades que estes profissionais podem encontrar, profissionais que atuam e que futuramente vão atuar diretamente nesse processo de cuidado. O presente estudo foi de grande relevância, não só por se tratar desta temática que é bem atual e que sempre gera indagações, mas foi também uma ótima oportunidade conhecer as reações e sentimentos que esses profissionais vivenciam nesse universo de cuidados paliativos. Acredito que sempre há uma forma de melhorar esse tipo de assistência.

\section{Referências}

Arrieira, I. C. O., Thofehrn, M. B., Porto, A. R., Moura, P. M. M., Martins, C. L., \& Jacondino, M. B. (2018). Espiritualidade nos cuidados paliativos: experiência vivida de uma equipe interdisciplinar. Revista da Escola de Enfermagem da USP, 52, e03312. https://doi.org/10.1590/s1980-220x2017007403312

Avanci, B. S., Carolindo, F. M., Góes, F. G. B., \& Cruz Netto, N. P. (2009). Cuidados paliativos à criança oncológica na situação do viver/morrer: a ótica do cuidar em enfermagem. Escola Anna Nery, 13(4), 708-716. https://doi.org/10.1590/S1414-81452009000400004

Barbosa, I. A., \& Silva, M. J. P. (2007). Cuidado humanizado de enfermagem: o agir com respeito em um hospital universitário. Revista Brasileira de Enfermagem, 60(5), 546-551. https://doi.org/10.1590/S0034-71672007000500012

Bardin, L. (2011). Análise de Conteúdo. Lisboa: Portugal: Edições 70 Ltda.

Capelas, D. M. L., Silva, S. C. F. S., Alvarenga, M. I. S. F. \& Coelho, S. P. (2016). Cuidados paliativos: O que é importante saber. Patient Care, 16-20.

Cardoso, D. H., Muniz, R. M., Schwartz, E., \& Arrieira, I. C. O. (2013). Cuidados paliativos na assistência hospitalar: a vivência de uma equipe multiprofissional. Texto \& Contexto - Enfermagem, 22(4), 1134-1141. https://dx.doi.org/10.1590/S0104-07072013000400032

Carvalho, R. T., \& Parsons, H. A. (2012). Manual de Cuidados Paliativos ANCP. São Paulo, ANCP.

Carvalho, V. A. (2006). Cuidados com o cuidador. In: Pessini, L., Bertachini, L. Humanização e cuidados paliativos. São Paulo, Loyola.

Cordeiro, A. L. \& Silva, D. A. (2020). Sobrecarga de familiares ao cuidar de um ente esquizofrênico. Revista INTELECTO, 3, 1-10.

Costa, Á. P., Poles, K., \& Silva, A. E. (2016). Formação em cuidados paliativos: experiência de alunos de medicina e enfermagem. Interface - Comunicação, Saúde, Educação, 20(59), 1041-1052. https://dx.doi.org/10.1590/1807-57622015.0774

Espíndola, A. V., Quintana, A. M., Farias, C. P., \& München, M. A. B. (2018). Relações familiares no contexto dos cuidados paliativos. Revista Bioética, 26(3), 371-377. https://doi.org/10.1590/1983-80422018263256

Franco, H. C. P., Stigar, R., Souza, S. J. P., \& Burci, L. M. (2017). Papel da enfermagem na equipe de cuidados paliativos: a humanização no processo de morte e morrer. Revista Gestão \& Saúde, 17(2), 48-61. 
Franco, M. H. P. (2005). Nada sobre mim sem mim: estudos sobre a vida e morte. Campinas: Editora Livro Pleno.

Freitas, N. O. \& Pereira, M. V. G. (2013). Percepção dos enfermeiros sobre cuidados paliativos e o manejo da dor na UTI. O Mundo da Saúde, 37(4), 450-457.

Gomes, A. L. Z., \& Othero, M. B. (2016). Cuidados paliativos. Estudos Avançados, 30(88), 155-166. https://doi.org/10.1590/s0103-40142016.30880011

Hermes, H. R., \& Lamarca, I. C. A. (2013). Cuidados paliativos: uma abordagem a partir das categorias profissionais de saúde. Ciência \& Saúde Coletiva, 18(9), 2577-2588. https://dx.doi.org/10.1590/S1413-81232013000900012

Julião, M., \& Barbosa, A. (2011). Depressão em cuidados paliativos: prevalência e avaliação. Acta Med Port, 24(S4), 807-818

Kruse, M. H. L., Vieira, R. W., Ambrosini, L., Niemeyer, F, \& Silva, F. P. (2007). Cuidados paliativos: uma experiência. Rev HCPA, $27(2)$, 49-52.

Luz, K. R., Vargas, M. A. O., Barlem, E. L. D., Schmitt, P. H., Ramos, F. R. S., \& Meirelles, B. H. S. (2016). Estratégias de enfrentamento por enfermeiros da oncologia na alta complexidade. Revista Brasileira de Enfermagem, 69(1), 67-71. https://dx.doi.org/10.1590/0034-7167.2016690109i

Markus, L. A., Betiolli, S. E., Souza, S. J. P., Marques, F. R., \& Migoto, M. T. (2017). A atuação do enfermeiro na assistência ao paciente em cuidados paliativos. Revista Gestão \& Saúde, 17(Supl 1), 71-81

Oliveira, É. A., Voltarelli, J. C., Santos, M. A., \& Mastropietro, A. P. (2005). Intervenção junto à família do paciente com alto risco de morte. Medicina (Ribeirão Preto), 38(1), 63-68. https://doi.org/10.11606/issn.2176-7262.v38i1p63-68

Oliveira, T. C. B., Maranhão, T. L. G., \& Barroso, M. L. (2017). Equipe multiprofissional de cuidados paliativos da oncologia pediátrica: uma revisão sistemática. Id on Line Multidisciplinary and Psycology Journal, 11(35), 492-530. https://doi.org/10.14295/idonline.v11i35.754

Paiva, F. C. L., Almeida Júnior, J. J., \& Damásio, A. C. (2014). Ética em cuidados paliativos: concepções sobre o fim da vida. Revista Bioética, 22(3), 550-560. https://dx.doi.org/10.1590/1983-80422014223038

Pereira, A. S., Shitsuka, D. M., Parreira, F. J., \& Shitsuka, R. (2018). Metodologia da pesquisa científica. [e-book]. Santa Maria. Ed. UAB/NTE/UFSM. Recuperado de: em: https://repositorio.ufsm.br/bitstream/handle/1/15824/Lic_Computacao_Metodologia-Pesquisa-Cientifica.pdf?sequence=1

Rezende, L. C. M., Costa, K. N. F. M., Martins, K. P., \& Costa, T. F. (2014) Comunicação entre a equipe de enfermagem e familiares de pacientes em unidade de terapia intensiva. Cultura de los Cuidados (Edición digital) 18, 39. http://dx.doi.org/10.7184/cuid.2014.39.10

Sampaio, S. G. S. M., Motta, L. B., \& Caldas, C. P. (2019). Medicamentos e Controle de dor: Experiência de um Centro de Referência em Cuidados Paliativos no Brasil. Revista Brasileira de Cancerologia, 65(2), e-13365. https://doi.org/10.32635/2176-9745.RBC.2019v65n2.365

Santana, J. C. B., Campos, A. C. V., Barbosa, B. D. G., Baldessari, C. E. F., Paula, K. F., Rezende, M. A. E., \& Dutra, B. S. (2009). Cuidados paliativos aos pacientes terminais: percepção da equipe de enfermagem. Bioethikos, 3(1), 77-86.

Santiago, E. J. P., Alves, N. C. C., Freire, A. K. S., \& Korinfsky, J. P. (2017). Enfermagem e cuidados paliativos, reconhecendo valores. Revista Saúde e Desenvolvimento, 11(9), 318-339.

Santos, J. B. S., Carvalho, D. M. S., Fonseca, M. M. \& Silva, F. P. (2017). Assistência integral de enfermagem aos pacientes em cuidados paliativos. Revista Saúde, 11(1).

Selli, A., \& Alves, J. S. (2007). O cuidado espiritual ao paciente terminal no exercício da enfermagem e a participação da bioética. Bioethikos, 1(1), 43-52.

Silva, D. A. (2020). O paciente com câncer e a espiritualidade: revisão integrativa. Revista Cuidarte, 11(3), e1107. https://doi.org/10.15649/cuidarte.1107

Silva, G. S. (2012). Em busca de uma configuração do real. In: Angerami-Camon, V. A. E a psicologia entrou no hospital. São Paulo, Cengage Learning.

Silveira, M. H., Ciampone, M. H. T., \& Gutierrez, B. A. O. (2014). Percepção da equipe multiprofissional sobre cuidados paliativos. Revista Brasileira de Geriatria e Gerontologia, 17(1), 7-16. https://doi.org/10.1590/S1809-98232014000100002

Silveira, N. R., Nascimento, E. R. P., Rosa, L. M., Jung, W., Martins, S. R., \& Fontes, M. S. (2016). Cuidado paliativo e enfermeiros de terapia intensiva: sentimentos que ficam. Revista Brasileira de Enfermagem, 69(6), 1074-1081. https://doi.org/10.1590/0034-7167-2016-0267

Tomaszewski, A. S., Oliveira, S. G., Arrieira, I. C. O., Cardosos, D. H., \& Sartor, S. F. (2017). Manifestações e necessidades referentes ao processo de morte e morrer: perspectiva da pessoa com câncer. Revista de Pesquisa: Cuidado é Fundamental Online, 9(3), 705-716. http://dx.doi.org/10.9789/21755361.2017.v9i3.705-716

Trindade, E. S., Azambuja, L. E. O., Andrade, J. P., \& Garrafa, V. (2007). O médico frente ao diagnóstico e prognóstico do câncer avançado. Revista da Associação Médica Brasileira, 53(1), 68-74. https://doi.org/10.1590/S0104-42302007000100023

Zombini, E. V., Bogus, C. M., Pereira, I. M. T. B., \& Pelicioni, M. C. F. (2012). Classe hospitalar: a articulação da saúde e educação como expressão da política de humanização do SUS. Trabalho, Educação e Saúde, 10(1), 71-86. https://dx.doi.org/10.1590/S1981-77462012000100005 